\title{
Combined effect of physical activity and leisure time sitting on long-term risk of incident obesity and metabolic risk factor clustering
}

\author{
Joshua A. Bell • Mark Hamer • G. David Batty • \\ Archana Singh-Manoux • Séverine Sabia • \\ Mika Kivimaki
}

Received: 16 April 2014 / Accepted: 16 June 2014 / Published online: 31 July 2014

(C) The Author(s) 2014. This article is published with open access at Springerlink.com

\begin{abstract}
Aims/hypothesis Our study aimed to investigate the combined effects of moderate-to-vigorous physical activity and leisure time sitting on the long-term risk of obesity and clustering of metabolic risk factors.

Methods The duration of moderate and vigorous physical activity and of leisure time sitting was assessed by questionnaire between 1997 and 1999 among 3,670 participants from the Whitehall II cohort study ( $73 \%$ male; mean age 56 years). Multivariable-adjusted logistic regression models examined associations of physical activity and leisure time sitting tertiles with odds of incident obesity (BMI $\geq 30 \mathrm{~kg} / \mathrm{m}^{2}$ ) and incident metabolic risk factor clustering (two or more of the following: low HDL-cholesterol, high triacylglycerol, hypertension, hyperglycaemia, insulin resistance) at 5 and 10 year follow-ups. Results Physical activity, but not leisure time sitting, was associated with incident obesity. The lowest odds of incident obesity after 5 years were observed for individuals reporting both high physical activity and low leisure time sitting $(\mathrm{OR}=$ 0.26 ; $95 \%$ CI $0.11,0.64)$, with weaker effects after 10 years. Compared with individuals in the low physical activity/high leisure time sitting group, those with intermediate levels of both physical activity and leisure time sitting had lower odds
\end{abstract}

Séverine Sabia and Mika Kivimaki are joint senior authors.

Electronic supplementary material The online version of this article (doi:10.1007/s00125-014-3323-8) contains peer-reviewed but unedited supplementary material, which is available to authorised users.

J. A. Bell $(\bowtie) \cdot$ M. Hamer $\cdot$ G. D. Batty $\cdot$ A. Singh-Manoux $\cdot$

S. Sabia $\cdot$ M. Kivimaki

Department of Epidemiology and Public Health, University College

London, 1-19 Torrington Place, London WC1E 6BT, UK

e-mail: joshua.bell.11@ucl.ac.uk

A. Singh-Manoux

INSERM, U1018, Centre for Research in Epidemiology and

Population Health, Villejuif, France of incident metabolic risk factor clustering after 5 years (OR $0.53 ; 95 \%$ CI $0.36,0.78)$, with similar odds after 10 years. Conclusions/interpretation Both high levels of physical activity and low levels of leisure time sitting may be required to substantially reduce the risk of obesity. Associations with developing metabolic risk factor clustering were less clear.

Keywords Epidemiology · Exercise · Metabolic syndrome Obesity . Weight regulation
Abbreviations
HOMA-IR HOMA of insulin resistance
MET Metabolic equivalent

\section{Introduction}

Obesity is associated with a clustering of metabolic abnormalities, such as hypertension, dyslipidaemia, insulin resistance and hyperglycaemia [1]. In general populations, however, metabolic risk factor clustering has been observed in both obese and non-obese adults $[2,3]$. The magnitude of longterm cardiovascular disease and mortality risk has been shown to depend on whether these factors are comorbid [4]. This suggests that obesity and metabolic risk factor clustering may be partly distinct clinical components of overall metabolic health.

Physical activity and sedentariness are two common lifestyle-related behaviours associated with both obesity and metabolic health, as well as with chronic diseases such as type 2 diabetes and cardiovascular disease, and with all-cause mortality [5-8]. Physical activity is assessed as movements of a light, moderate or vigorous intensity, requiring a metabolic equivalent (MET) value of at least 1.6 units. Sedentary behaviour, or 'sitting', in turn refers to the absence of 
movement, requiring $\leq 1.5$ METs [9], and may influence health independently through mechanisms such as dysregulation of lipoprotein lipase activity and inflammation $[6,10]$, or simply through displacement of moderate-to-vigorous physical activity [11].

There is evidence, although mostly cross-sectional, that physical activity is more strongly associated with obesity than is sitting $[12,13]$ and that these behaviours are associated with metabolic risk factors including blood pressure, plasma lipids, blood glucose and insulin [6, 14-17]. However, there is limited prospective evidence to support their role as protective factors against future weight gain and obesity [18-20]. Physical activity has been associated with a reduced risk of developing metabolic risk factor clustering [21, 22], while sitting has been associated with an increased risk [23, 24].

Studies often consider physical activity and sitting individually; however, these behaviours are closely linked, with modern-day inactive lifestyles being characterised by both insufficient physical activity and excessive leisure time sitting [25]. Evidence on their combined effects is limited and it is difficult to infer the causal direction of effects on overweight [26] or obesity [27, 28] from cross-sectional studies. One prospective study found that the combination of high physical activity and low sitting is associated with a lower risk of developing obesity [29]. Their combined effect on the risk of developing metabolic risk factor clustering, however, has not been investigated. Furthermore, the relative importance of physical activity and leisure time sitting combinations in relation to the development of obesity and metabolic risk factor clustering has not been studied within a single analytical framework.

This study aimed to clarify these associations by prospectively investigating the long-term risk of incident obesity and incident metabolic risk factor clustering among adults with different levels and combinations of physical activity and leisure time sitting.

\section{Methods}

Study population The Whitehall II study is an occupational cohort study of British civil servants (government employees) in which 10,308 men and women were recruited between 1985 and 1988 [30]. Participants have been followed up every 5 years with clinical examinations. Data on sitting time were first recorded in 1997-1999, which served as the baseline for this study. Participants provided written informed consent. Ethical approval was obtained from the University College London Research Ethics Committee.

Physical activity and leisure time sitting As part of the 19971999 questionnaire, physical activity was assessed using a modified 20-item version of the validated Minnesota Leisure
Time Physical Activity Questionnaire [31-33]. Participants reported the frequency and duration of various activities including sports, walking, cycling, home maintenance and gardening. Duration of moderate-to-vigorous physical activity ( $\geq 3$ METs) was used in analyses and classified into tertiles (low, 0-1.50 h/week; intermediate, 1.56-4.25 h/week; high, 4.27-20.56 h/week). Participants were also asked: 'On average, how many hours a week do you spend sitting at home, e.g. watching TV, sewing, at a desk?', for which participants selected one of eight responses: none, 1, 2-5, 6-10, 11-20, $21-30,31-40,40+\mathrm{h}$. The midpoint for each time slot was summed to form a continuous scale, with each unit representing a $1 \mathrm{~h}$ change in sitting time. Total leisure time sitting was then divided into tertiles (low, $0-11.5 \mathrm{~h} / \mathrm{week}$; intermediate, 15-23 h/week; high, 25-90 h/week). Tertiles of physical activity and leisure time sitting were further combined to form nine groups. 'Low activity/high sitting' was used as the reference group, representing the assumed lowest level of energy expenditure and, thus, the least favourable combination.

Incident obesity Objectively measured anthropometrics were assessed in 1997-1999 (baseline), 2002-2004 (5 year followup) and 2007-2009 (10 year follow-up) and used to compute BMI using the standard formula: weight in kilograms divided by the square of height in metres. Obesity was defined as $B M I \geq 30 \mathrm{~kg} / \mathrm{m}^{2}$ (with 'non-obese' defined as $\mathrm{BMI}<30 \mathrm{~kg} / \mathrm{m}^{2}$ ).

Incident metabolic risk factor clustering Objectively measured metabolic risk factors were assessed in 1997-1999 (baseline), 2002-2004 (5 year follow-up) and 2007-2009 (10 year follow-up) and used to define metabolic health status based on comprehensive criteria [2]. 'Metabolic risk factor clustering' was defined as having two or more of the following risk factors: HDL-cholesterol $<1.03 \mathrm{mmol} / \mathrm{l}$ for men and $<1.29 \mathrm{mmol} / \mathrm{l}$ for women; blood pressure $\geq 130 / 85 \mathrm{mmHg}$ or taking antihypertensive medication; fasting plasma glucose $\geq 5.6 \mathrm{mmol} / \mathrm{l}$ or taking diabetic medication; triacylglycerol $\geq 1.7 \mathrm{mmol} / \mathrm{l}$; HOMA of insulin resistance (HOMA-IR) $>3.20$ (90th percentile value in 1997-1999).

Covariates Covariates used in the present analyses were assessed in 1997-1999 and included age, sex and ethnicity ('non-white', 'white'), socioeconomic status as indicated by British civil service occupational position ('administrative', 'professional/executive', 'clerical/support'), health status as represented by the self-reported presence of a long-standing illness ('yes', 'no'), and health behaviours as indicated by frequency of fruit and vegetable consumption ('at least one serving per day'; 'less than one serving per day'), cigarette smoking status ('never smoker', 'ex-smoker', 'current smoker') and units of alcohol consumed in the previous week. 
Statistical analyses Logistic regression models were used to compute ORs with accompanying $95 \%$ CIs as estimates of associations of physical activity and leisure time sitting, separately and in combination, with incident obesity and incident metabolic risk factor clustering at 5 and 10 years of follow-up. The 10 year follow-up assessed the cumulative incidence for each outcome, considering changes at 5 or 10 years. Participants who were obese at baseline were excluded from analyses for incident obesity. Likewise, participants with metabolic risk factor clustering at baseline were excluded from analyses for incident metabolic risk factor clustering. Estimates were first adjusted for age, sex and ethnicity (the minimally adjusted model), and then further adjusted for occupational position, health status and health behaviours (the multivariable-adjusted model). If data were unavailable for health behaviour covariates at the 1997-1999 assessment, data from 1991-1994 were used. Statistical interaction between physical activity and leisure time sitting was tested by including the product term of the corresponding tertiles in relation to each outcome in logistic regression models. Analyses were performed using SPSS software, version 19 (IBM SPSS, Armonk, NY, USA), with two-tailed $p<0.05$ indicating statistical significance.

Sensitivity analyses In order to investigate adverse metabolic change in greater detail, we used linear regression models to further estimate associations of physical activity and leisure time sitting, separately and in combination, with change in the number of metabolic risk factors (including obesity; range 0 6) between baseline and follow-up. The number of risk factors (high blood pressure, high blood glucose, high triacylglycerol, low HDL-cholesterol, insulin resistance and obesity) at baseline was subtracted from the number of risk factors in 20022004 to estimate the difference after 5 years. Likewise, the number of risk factors at baseline was subtracted from the number of risk factors in 2007-2009 to estimate 10 year changes. A positive value indicated an increase in the number of risk factors over time, whereas a negative value indicated a decrease in the number of risk factors over time.

\section{Results}

Sample characteristics The study sample (defined as the group of participants with data on physical activity and leisure time sitting at baseline, and obesity status, metabolic risk factors and covariates at baseline and 5 years of follow-up) comprised 3,670 individuals. This group was approximately three-quarters male, with a mean age of 55.5 (SD 6.0) years at baseline. Compared with individuals included in analyses, those excluded were more likely to be women $(36.2 \%$ vs $27.5 \% ; p<0.001)$, of a non-white ethnicity $(13.1 \%$ vs $7.0 \%$; $p<0.001)$ and from the lowest occupational position group $(18.3 \%$ vs $11.0 \% ; p<0.001)$.

As shown in Table $1,17.6 \%$ of the low physical activity group was considered obese, compared with $11.4 \%$ of those in the high physical activity group $(p<0.05)$. The baseline prevalence of obesity was similar in the low (12.1\%) and high leisure time sitting groups $(14.4 \% ; p>0.05)$. Nearly $36 \%$ of individuals in the low physical activity group had metabolic risk factor clustering at baseline, compared with approximately $28 \%$ in the high physical activity group $(p<0.05)$. Conversely, nearly $34 \%$ of the high leisure time sitting group had metabolic risk factor clustering, compared with about $30 \%$ of those in the low leisure time sitting group $(p>0.05)$.

Incident obesity As shown in Table 1, the rate of incident obesity was lower in the high compared with the low physical activity group after 5 years $(4.8 \%$ vs $8.0 \% ; p<0.05)$ and after 10 years $(6.9 \%$ vs $11.9 \% ; p<0.05)$. Incident obesity did not differ by level of leisure time sitting at either follow-up $(p>0.05)$. Compared with having a low level of physical activity, having a high level was associated with $0.64(95 \%$ CI $0.44,0.93$ ) times lower odds of incident obesity after 5 years, with $0.63(95 \%$ CI $0.45,0.88)$ times lower odds after 10 years in models adjusted for age, sex and ethnicity (electronic supplementary material [ESM] Table 1). In multivariable-adjusted models (Table 2), lower odds of incident obesity were observed with increasing levels of physical activity independently of leisure time sitting after 10 years only ( $p$ for trend $=0.02$ ). Compared with being in the low physical activity group, being in the intermediate and the high group was associated with $0.66(95 \% \mathrm{CI} 0.47,0.91)$ and 0.67 $(95 \%$ CI $0.48,0.95)$ times lower odds of incident obesity after 10 years, respectively. Leisure time sitting level was not associated with incident obesity at either follow-up.

Compared with the combination of low physical activity and high leisure time sitting, most groups trended towards lower odds of incident obesity, but the combination of high physical activity and low leisure time sitting was associated with the lowest odds after 5 years (OR 0.23 ; $95 \%$ CI 0.10 , 0.57 ) and after 10 years (OR $0.47 ; 95 \%$ CI $0.24,0.91$ ) in minimally adjusted models (ESM Table 2). Lower odds of incident obesity were observed for increasing levels of physical activity only within the low leisure time sitting group ( $p$ for trend $=0.001$ ); and similarly lower odds of incident obesity were observed for decreasing levels of leisure time sitting only within the high physical activity group ( $p$ for trend $=0.01 ; p$ for interaction $=0.02$ after 5 years $)$. In multivariable-adjusted models (Table 3 ), only the combination of high physical activity and low leisure time sitting was associated with lower odds of incident obesity after 5 years (OR 0.26; 95\% CI 0.11, 0.64). This result was also observed after 10 years, although the effect size was smaller (OR 0.51; $95 \%$ CI $0.26,1.00 ; p=0.05 ; p$ for interaction $=0.37$ ). 
Table 1 Characteristics of participants in the Whitehall II cohort study by level of physical activity and leisure time sitting $(N=3,670)$

\begin{tabular}{|c|c|c|c|c|c|c|}
\hline \multirow[t]{2}{*}{ Characteristic } & \multicolumn{3}{|c|}{ Physical activity level } & \multicolumn{3}{|c|}{ Leisure time sitting level } \\
\hline & $\begin{array}{l}\text { Low } \\
(n=1,205)\end{array}$ & $\begin{array}{l}\text { Intermediate } \\
(n=1,254)\end{array}$ & $\begin{array}{l}\text { High } \\
(n=1,211)\end{array}$ & $\begin{array}{l}\text { High } \\
(n=1,336)\end{array}$ & $\begin{array}{l}\text { Intermediate } \\
(n=1,311)\end{array}$ & $\begin{array}{l}\text { Low } \\
(n=1,023)\end{array}$ \\
\hline \multicolumn{7}{|l|}{ Baseline } \\
\hline Male, $n(\%)$ & $706(58.6)$ & $917(73.1)^{*}$ & $1,037(85.6)^{*}$ & $995(74.5)$ & $955(72.8)$ & $710(69.4)^{\dagger}$ \\
\hline Age, years & $54.8(5.7)$ & $55.0(5.9)$ & $56.7(6.0)^{*}$ & $56.6(6.0)$ & $54.8(5.9)^{\dagger}$ & $54.9(5.7)^{\dagger}$ \\
\hline Non-white ethnicity, $n(\%)$ & $154(12.8)$ & $66(5.3)^{*}$ & $36(3.0)^{*}$ & $75(5.6)$ & $69(5.3)$ & $112(10.9)^{\dagger}$ \\
\hline Lowest employment grade, $n(\%)$ & $244(20.2)$ & $114(9.1)^{*}$ & $46(3.8)^{*}$ & $134(10)$ & $118(9.0)$ & $152(14.9)^{\dagger}$ \\
\hline Systolic blood pressure, $\mathrm{mmHg}$ & $122.5(16.5)$ & $122.0(15.9)$ & $123.5(16.0)$ & $123.2(15.9)$ & $122.3(16.4)$ & $122.5(16.1)$ \\
\hline Diastolic blood pressure, $\mathrm{mmHg}$ & $77.3(10.3)$ & $77.5(10.5)$ & $77.6(10.4)$ & $77.7(10.2)$ & $77.3(10.6)$ & $77.4(10.5)$ \\
\hline HDL-cholesterol, mmol/1 & $1.5(0.4)$ & $1.5(0.4)$ & $1.5(0.4)$ & $1.4(0.4)$ & $1.5(0.4)$ & $1.5(0.4)$ \\
\hline Fasting glucose, mmol/1 & $5.2(1.1)$ & $5.1(0.8)$ & $5.2(1.0)$ & $5.2(0.9)$ & $5.2(0.9)$ & $5.2(1.2)$ \\
\hline HOMA-IR & $2.7(6.3)$ & $2.1(2.5)^{*}$ & $2.1(3.6)^{*}$ & $2.4(5.5)$ & $2.2(2.8)$ & $2.3(4.5)$ \\
\hline Triacylglycerol, mmol/1 & $1.4(0.9)$ & $1.3(0.9)^{*}$ & $1.3(0.8)^{*}$ & $1.4(0.9)$ & $1.3(0.8)^{\dagger}$ & $1.3(0.8)^{\dagger}$ \\
\hline At least one fruit/vegetable serving per day, $n(\%)$ & $815(67.6)$ & $956(76.2)^{*}$ & $963(79.5)^{*}$ & $1,011(75.7)$ & $986(75.2)$ & $737(72.0)^{\dagger}$ \\
\hline Current smoker, $n(\%)$ & $137(11.4)$ & $103(8.2)^{*}$ & $69(5.7)^{*}$ & $130(9.7)$ & $103(7.9)$ & $76(7.4)$ \\
\hline Alcohol units in previous week & $12.4(15.9)$ & $13.7(14.6)^{*}$ & $15.5(14.6)^{*}$ & $14.6(16.0)$ & $14.1(13.9)$ & $12.8(15.3)^{\dagger}$ \\
\hline Obese, $n(\%)$ & $212(17.6)$ & $160(12.8)^{*}$ & $138(11.4)^{*}$ & $193(14.4)$ & $193(14.7)$ & $124(12.1)$ \\
\hline Metabolic risk factor clustering, $n(\%)$ & $429(35.6)$ & $377(30.1)^{*}$ & $335(27.7)^{*}$ & $447(33.5)$ & $389(29.7)^{\dagger}$ & $305(29.8)$ \\
\hline \multicolumn{7}{|l|}{ Adverse metabolic changes at follow-up } \\
\hline Incident obesity after 5 years, $n(\%)^{\mathrm{a}}$ & $79(8.0)$ & $63(5.8)^{*}$ & $52(4.8)^{*}$ & $74(6.5)$ & $60(5.4)$ & $60(6.7)$ \\
\hline Incident obesity after 10 years, $n(\%)^{\mathrm{b}}$ & $101(11.9)$ & $72(7.6)^{*}$ & $68(6.9)^{*}$ & $84(8.4)$ & $83(8.3)$ & $74(9.5)$ \\
\hline Incident metabolic risk factor clustering after 5 years, $n(\%)^{\mathrm{c}}$ & $183(23.6)$ & $170(19.4)^{*}$ & $198(22.6)$ & $223(25.1)$ & $182(19.7)^{\dagger}$ & $146(20.3)^{\dagger}$ \\
\hline Incident metabolic risk factor clustering after 10 years, $n(\%)^{\mathrm{d}}$ & $229(33.6)$ & $217(28.2)^{*}$ & $252(31.3)$ & $274(34.8)$ & $238(28.5)^{\dagger}$ & $186(29.4)^{\dagger}$ \\
\hline
\end{tabular}

Levels are based on tertiles; values are mean (SD) unless otherwise noted

${ }^{\text {a }}$ Sample size $=3,160$

${ }^{\mathrm{b}}$ Sample size $=2,778$

${ }^{\mathrm{c}}$ Sample size $=2,529$

${ }^{\mathrm{d}}$ Sample size $=2,254$

* Significantly different from low physical activity group $(p<0.05)$

${ }^{\dagger}$ Significantly different from high leisure time sitting group $(p<0.05)$

Incident metabolic risk factor clustering As shown in Table 1, incident metabolic risk factor clustering after 5 or 10 years was less prevalent in the intermediate compared with the low physical activity group $(p<0.05)$, while this was not observed for the high physical activity group $(p>0.05)$. Incident metabolic risk factor clustering was less prevalent in the low compared with the high leisure time sitting group after 5 years $(20.3 \%$ vs $25.1 \% ; p<0.05)$ and after 10 years $(29.4 \%$ vs $34.8 \% ; p<0.05)$. In models adjusted for age, sex and ethnicity (ESM Table 1), being in the intermediate physical activity group was associated with lower odds of incident metabolic risk factor clustering after 5 years (OR 0.76; 95\% CI 0.60, 0.97 ) and after 10 years (OR 0.75 ; 95\% CI $0.60,0.94$ ), independently of leisure time sitting. Similarly reduced odds were observed for intermediate levels of physical activity in multivariable-adjusted models (Table 2). Estimates for the high physical activity group were consistently below 1.00 , but did not reach statistical significance at conventional levels at either follow-up point. Compared with being in the high leisure time sitting group, being in the intermediate group was associated with lower odds of incident metabolic risk factor clustering after 5 years (OR 0.79; 95\% CI $0.63,0.99)$ and after 10 years (OR 0.78 ; 95\% CI $0.63,0.97)$ in multivariableadjusted models.

Compared with the combination of low physical activity and high leisure time sitting, most groups trended towards lower odds of incident metabolic risk factor clustering after 5 and 10 years, adjusting for age, sex and ethnicity (ESM Table 2); however, the greatest reduction in odds was observed for the intermediate physical activity/low leisure time sitting combination (OR $0.50 ; 95 \%$ CI $0.33,0.76$ ) after 5 years and the intermediate physical activity/intermediate leisure time sitting combination after 10 years (OR $0.52 ; 95 \%$ CI $0.36,0.76$ ). In multivariable-adjusted models (Table 4), the 
Table 2 Separate associations of physical activity and leisure time sitting level at baseline with incident obesity and incident metabolic risk factor clustering at follow-up

\begin{tabular}{|c|c|c|c|c|}
\hline & \multicolumn{2}{|l|}{$\begin{array}{l}\text { Incident obesity } \\
\text { OR }(95 \% \mathrm{CI})\end{array}$} & \multicolumn{2}{|c|}{$\begin{array}{l}\text { Incident metabolic risk factor clustering } \\
\text { OR }(95 \% \mathrm{CI})\end{array}$} \\
\hline & After 5 years $(n=3,160)$ & After 10 years $(n=2,778)$ & After 5 years $(n=2,529)$ & After 10 years $(n=2,254)$ \\
\hline \multicolumn{5}{|c|}{ Physical activity level } \\
\hline Low & 1.00 (reference) & 1.00 (reference) & 1.00 (reference) & 1.00 (reference) \\
\hline Intermediate & $0.76(0.53,1.08)$ & $0.66(0.47,0.91)$ & $0.77(0.60,0.98)$ & $0.76(0.60,0.95)$ \\
\hline High & $0.70(0.47,1.03)$ & $0.67(0.48,0.95)$ & $0.87(0.68,1.12)$ & $0.85(0.67,1.07)$ \\
\hline$p$ for trend & 0.06 & 0.02 & 0.33 & 0.21 \\
\hline \multicolumn{5}{|c|}{ Leisure time sitting level } \\
\hline High & 1.00 (reference) & 1.00 (reference) & 1.00 (reference) & 1.00 (reference) \\
\hline Intermediate & $0.80(0.56,1.15)$ & $0.96(0.69,1.32)$ & $0.79(0.63,0.99)$ & $0.78(0.63,0.97)$ \\
\hline Low & $1.01(0.71,1.45)$ & $1.10(0.79,1.55)$ & $0.83(0.65,1.06)$ & $0.83(0.65,1.04)$ \\
\hline$p$ for trend & 0.96 & 0.64 & 0.09 & 0.07 \\
\hline
\end{tabular}

Separate associations are mutually adjusted; models adjusted for age, sex, ethnicity, occupational position, frequency of fruit and vegetable consumption, smoking status, alcohol consumption and the presence of a long-standing illness

lowest odds of incident metabolic risk factor clustering were observed for the intermediate physical activity/intermediate leisure time sitting combination after 5 years (OR $0.53 ; 95 \%$ CI $0.36,0.78 ; p$ for interaction $=0.35)$ and after 10 years $(\mathrm{OR}$ $0.53 ; 95 \%$ CI $0.36,0.77 ; p$ for interaction $=0.47$ ).

Sensitivity analyses Sensitivity analyses examining continuous change in the number of metabolic risk factors (including obesity) suggested that neither high physical activity nor low leisure time sitting were independently associated with change in the number of metabolic risk factors after 5 or 10 years (ESM Tables 3, 4). No combination of physical activity and leisure time sitting was associated with change in the number of metabolic risk factors after 5 or 10 years.

\section{Discussion}

This study prospectively examined the combined effect of moderate-to-vigorous physical activity and leisure time sitting on the long-term risk of two related adverse metabolic changes: obesity and metabolic risk factor clustering. High levels of physical activity were associated with a slightly reduced risk of becoming obese after 10 years of follow-up; however, the combined effect of high physical activity and low leisure time sitting after 5 years was much larger, suggesting a substantially reduced risk of developing obesity for highly active individuals who also engage in low amounts of sitting in their leisure time. No such interaction was observed in relation to incident metabolic risk factor clustering: physical activity and

Table 3 Combined associations of physical activity and leisure time sitting level at baseline with incident obesity at follow-up

\begin{tabular}{|c|c|c|c|c|c|c|c|c|}
\hline \multirow[b]{4}{*}{ Physical activity level } & \multicolumn{8}{|c|}{$\begin{array}{l}\text { Incident obesity } \\
\text { Odds ratio }(95 \% \mathrm{CI})\end{array}$} \\
\hline & \multicolumn{3}{|l|}{$\begin{array}{l}\text { After } 5 \text { years } \\
n=3,160\end{array}$} & \multirow[b]{3}{*}{$p$-trend } & \multicolumn{3}{|l|}{$\begin{array}{l}\text { After } 10 \text { years } \\
n=2,778\end{array}$} & \multirow[b]{3}{*}{$p$-trend } \\
\hline & \multicolumn{3}{|c|}{ Leisure time sitting level } & & \multicolumn{3}{|c|}{ Leisure time sitting level } & \\
\hline & High & Intermediate & Low & & High & Intermediate & Low & \\
\hline Low & 1.00 (reference) & $0.64(0.36,1.15)$ & $1.11(0.64,1.93)$ & 0.85 & 1.00 (reference) & $0.91(0.55,1.53)$ & $1.31(0.78,2.20)$ & 0.35 \\
\hline Intermediate & $0.55(0.30,1.02)$ & $0.55(0.30,1.00)$ & $0.99(0.57,1.71)$ & 0.07 & $0.60(0.33,1.07)$ & $0.65(0.38,1.13)$ & $0.84(0.49,1.45)$ & 0.36 \\
\hline High & $0.81(0.46,1.43)$ & $0.72(0.40,1.29)$ & $0.26(0.11,0.64)$ & 0.02 & $0.81(0.48,1.39)$ & $0.74(0.43,1.27)$ & $0.51(0.26,1.00)$ & 0.21 \\
\hline$p$-trend & 0.43 & 0.47 & 0.002 & & 0.39 & 0.59 & 0.01 & \\
\hline$p$-interaction & & 0.02 & & & & 0.37 & & \\
\hline
\end{tabular}

Models adjusted for age, sex, ethnicity, occupational position, frequency of fruit and vegetable consumption, smoking status, alcohol consumption and the presence of a long-standing illness. 
Table 4 Combined associations of physical activity and leisure time sitting level at baseline with incident metabolic risk factor clustering at follow-up

Incident metabolic risk factor clustering Odds ratio $(95 \% \mathrm{CI})$

\begin{tabular}{|c|c|c|c|c|c|c|c|c|}
\hline \multirow[b]{3}{*}{ Physical activity level } & \multicolumn{3}{|l|}{$\begin{array}{l}\text { After } 5 \text { years } \\
n=2,529\end{array}$} & \multirow[b]{3}{*}{$p$-trend } & \multicolumn{3}{|l|}{$\begin{array}{l}\text { After } 10 \text { years } \\
n=2,254\end{array}$} & \multirow[b]{3}{*}{$p$-trend } \\
\hline & \multicolumn{3}{|c|}{ Leisure time sitting level } & & \multicolumn{3}{|c|}{ Leisure time sitting level } & \\
\hline & High & Intermediate & Low & & High & Intermediate & Low & \\
\hline Low & 1.00 (reference) & $0.64(0.43,0.95)$ & $0.74(0.48,1.13)$ & 0.12 & 1.00 (reference) & $0.70(0.47,1.02)$ & $0.84(0.55,1.27)$ & 0.31 \\
\hline Intermediate & $0.75(0.51,1.10)$ & $0.53(0.36,0.78)$ & $0.54(0.35,0.82)$ & 0.11 & $0.81(0.56,1.19)$ & $0.53(0.36,0.77)$ & $0.57(0.38,0.85)$ & 0.08 \\
\hline High & $0.67(0.45,0.98)$ & $0.71(0.49,1.05)$ & $0.70(0.46,1.05)$ & 0.79 & $0.72(0.50,1.04)$ & $0.72(0.50,1.05)$ & $0.68(0.45,1.02)$ & 0.77 \\
\hline$p$-trend & 0.01 & 0.49 & 0.45 & & 0.10 & 0.97 & 0.82 & \\
\hline$p$-interaction & & 0.35 & & & & 0.47 & & \\
\hline
\end{tabular}

Models adjusted for age, sex, ethnicity, occupational position, frequency of fruit and vegetable consumption, smoking status, alcohol consumption and the presence of a long-standing illness.

leisure time sitting each showed comparable associations with risk of incident metabolic risk factor clustering, with reduced risk observed for intermediate levels only. These results were robust to adjustment for a wide range of potentially confounding factors, including socioeconomic status, smoking behaviour, alcohol consumption and health status.

The present findings, based on longitudinal comparisons of separate and combined associations of physical activity and leisure time sitting, add to the literature by suggesting that the combination of high physical activity and low leisure time sitting is a stronger protective factor against becoming obese than either behaviour on its own. This finding is in agreement with previous studies. In a recent investigation of young adults, for example, increased physical activity reduced the risk of becoming obese after 5 years only within individuals who also showed lower screen-based sitting time; although this association was observed in females only [29].

The mechanisms underlying this interaction are unclear. In principle, lower levels of leisure time sitting may strengthen protective effects of higher physical activity, either through independent physiological mechanisms [6] or as a marker for greater engagement in low-intensity activity, such as standing [34]. Physical activity and leisure time sitting combinations may also simply represent incremental increases in energy expenditure, with the lowest physical activity/highest leisure time sitting group expending the least amount of energy overall, and the highest physical activity/lowest leisure time sitting group expending the most. In the present study, associations of physical activity and leisure time sitting combinations on risk of incident obesity were strongest after 5 years, with effects appearing weaker at a longer 10 year follow-up point. The dilution of effects over time might be due to misclassification errors resulting from changes in physical activity and leisure time sitting during the follow-up period [35] which were not possible to consider in the present study.
Our findings on incident metabolic risk factor clustering did not follow a pattern of additive interaction or doseresponse. The greatest reduction in risk observed for intermediate levels of physical activity and leisure time sitting was unexpected and suggests that moderate amounts of both moderate-to-vigorous physical activity and leisure time sitting may be sufficient to protect against developing metabolic risk factor clustering over time. Results from previous studies on the interactive nature of physical activity and sitting with metabolic risk factor clustering are mixed. In some crosssectional studies, higher sitting time was associated with metabolic risk factor clustering independently of physical activity $[16,36]$, while other studies suggest that the strength of the association between sitting and metabolic risk depends upon engagement in physical activity $[37,38]$. Some prospective studies have suggested that higher objectively measured sitting time is associated with worsening insulin profiles [39] and with metabolic risk factor clustering [24] independently of moderate-to-vigorous physical activity, while others reported that increased television viewing time [40] and low physical activity both independently predicted worsening metabolic profiles after several years of follow-up.

The combined effects of physical activity and leisure time sitting on developing metabolic risk factor clustering have not been previously examined; however, results of present analyses seem discordant with expected patterns, given known dose-response associations of moderate-to-vigorous physical activity on risk of metabolic risk factor clustering and related diseases [8, 21, 22]. The U-shaped pattern of results presently observed may be due to chance or to residual confounding. Obese individuals at baseline were included in analyses of incident metabolic risk factor clustering. The proportion of participants with intermediate levels of physical activity and sitting who were obese was, however, greater than those with high activity and low sitting (Table 1); thus, confounding by 
BMI is unlikely. Antihypertensive and diabetic drug use formed part of the criteria for metabolic risk factor clustering; however, data on lipid-lowering drug use were not considered. Wider use of such medication by participants in intermediate groups could help explain their reduced risk of metabolic risk factor clustering. Another possible explanation involves misclassification errors resulting from changes in physical activity and leisure time sitting over time. For instance, participants reporting high physical activity and low leisure time sitting at baseline may have worsened their activity profile after this assessment, thus making their risk of metabolic risk factor clustering comparable to that of inactive individuals. 'Metabolic risk factor clustering' was treated as a binary outcome in the main analyses, the results of which may depend upon the specific cut-points chosen. To examine this possibility, we performed sensitivity analyses investigating associations of physical activity and leisure time sitting with change in the number of metabolic risk factors over time, with obesity included as one of six factors of interest. Results of these analyses fail to support physical activity and leisure time sitting as factors involved in the accumulation of metabolic risk factors. Strong effects were therefore observed for becoming obese when obesity was considered on its own, but not when grouped as one of several components of metabolic risk factor clustering. This finding is consistent with main analyses suggesting weaker results for metabolic risk factor clustering compared with the obesity outcome.

Associations of sedentary behaviour with metabolic risk may depend on the measure which is employed. For instance, associations are often weak or non-existent when using sitting in an occupational context as a marker of sedentary time [41, 42], while detrimental associations with abnormal glucose metabolism [43], insulin resistance, dyslipidaemia [44] and metabolic clustering $[17,37,44]$ are widely reported when using self-reported television viewing as an indicator of sitting. We used a measure of total leisure time sitting in the present study, which may provide better insight into overall effects of sitting on adverse metabolic change than measures which are context-specific. In a related sense, the modern paradigm of sedentary behaviour as an independent health risk is based largely on observations that higher levels of sitting remain associated with metabolic risk factors after statistically accounting for engagement in moderate-tovigorous activity [45]. However, independent associations of sitting on metabolic risk are less evident when adjusting for broader incidental measures of light intensity physical activity. For instance, when adjusting for total activity as objectively measured by accelerometry (and not moderate or vigorous activity only), associations between total sitting time and metabolic risk factors, including inflammatory markers and blood lipids, were no longer evident [46]. Nevertheless, light physical activity and sitting are highly correlated and are thus difficult to model together.
Strengths and limitations Main strengths of this study include a large sample size, a prospective design with follow-up extending to 10 years, and objective measures of anthropometrics and metabolic risk factors. We had the advantage of assessing incident obesity and incident metabolic risk factor clustering in the same study, thus affording direct comparisons between the two outcomes. Physical activity and leisure time sitting were measured on a continuous scale, allowing the use of percentile groups to better examine dose-response associations. Metabolic risk factor clustering was defined in this study according to comprehensive criteria used in previous work on the general US population [2]; however, C-reactive protein was not included as part of our definition as it was not available at the 10 year follow-up. Diet quality was assessed via frequency of fruit and vegetable consumption and may be subject to residual confounding by other aspects of diet such as excessive fat or sugar intake [47]. Measures of physical activity and leisure time sitting were taken at baseline only and are thus subject to misclassification errors if these are unstable over the course of follow-up [35]. Physical activity and leisure time sitting were self-reported and thus subject to biases. In particular, self-reported sitting time tends to be only moderately correlated with objective assessments [48]. However, given that subjective measures of physical activity and sitting have shown weaker and less consistent associations with metabolic risk factors compared with objective measures $[48,49]$, associations observed in present analyses may be, if anything, underestimates of true effects. Longitudinal studies using objective measures of physical activity and leisure time sitting combinations are needed to confirm these findings.

Conclusions The protective effects of moderate-to-vigorous physical activity and low leisure time sitting against developing obesity and metabolic risk factor clustering are strongest when viewed in combination. The interaction observed supports the notion that both high levels of physical activity and low levels of leisure time sitting may be required to substantially reduce the risk of developing obesity. Associations with developing metabolic risk factor clustering were less clear. Intervention studies are needed to examine whether adverse metabolic changes in the form of obesity and metabolic risk factor clustering are best prevented by improving levels of both physical activity and leisure time sitting.

Acknowledgements We thank all the participating civil service departments and their welfare, personnel and establishment officers; the British Occupational Health and Safety Agency; the British Council of Civil Service Unions; all participating civil servants in the Whitehall II study; and all members of the Whitehall II study team. The Whitehall II study team comprises research scientists, statisticians, study coordinators, nurses, data managers, administrative assistants and data entry staff, who make the study possible. 
Funding JAB is supported by an Economic and Social Research Council studentship. MH is supported by the British Heart Foundation (RE/10/005/28296). AS-M receives research support from the US National Institutes of Health (R01AG013196, R01AG034454). SS is supported by the National Institute on Aging. MK is supported by the Medical Research Council (K013351); the National Heart, Lung, and Blood Institute (R01HL36310); the National Institute of Aging (R01AG034454); the Academy of Finland; and an ESRC professorial fellowship. The funders had no role in the study design; in the collection, analysis and interpretation of data; in writing of the report; or in the decision to submit the paper for publication. The developers and funders of the Whitehall II study do not bear any responsibility for the analyses or interpretations presented here.

Duality of interest The authors declare that there is no duality of interest associated with this manuscript.

Contribution statement $\mathrm{JAB}$ had full access to the data and takes primary responsibility for the accuracy and integrity of the results. JAB performed analyses and wrote the first draft. All authors contributed to the study concept and design, and critical revision of the manuscript. All authors approved the final manuscript.

Open Access This article is distributed under the terms of the Creative Commons Attribution License which permits any use, distribution, and reproduction in any medium, provided the original author(s) and the source are credited.

\section{References}

1. Alberti K, Eckel RH, Grundy SM et al (2009) Harmonizing the metabolic syndrome: a joint interim statement of the International Diabetes Federation Task Force on Epidemiology and Prevention; National Heart, Lung, and Blood Institute; American Heart Association; World Heart Federation; International Atherosclerosis Society; and International Association for the Study of Obesity. Circulation 120:1640-1645

2. Wildman RP, Muntner P, Reynolds K et al (2008) The obese without cardiometabolic risk factor clustering and the normal weight with cardiometabolic risk factor clustering: prevalence and correlates of 2 phenotypes among the US population (NHANES 1999-2004). Arch Intern Med 168:1617-1624

3. Iacobellis G, Ribaudo MC, Zappaterreno A, Iannucci CV, Leonetti F (2005) Prevalence of uncomplicated obesity in an Italian obese population. Obes Res 13:1116-1122

4. Kramer CK, Zinman B, Retnakaran R (2013) Are metabolically healthy overweight and obesity benign conditions? A systematic review and meta-analysis. Ann Intern Med 159:758-769

5. Wilmot E, Edwardson C, Achana F et al (2012) Sedentary time in adults and the association with diabetes, cardiovascular disease and death: systematic review and meta-analysis. Diabetologia 1-11

6. Hamilton MT, Hamilton DG, Zderic TW (2007) Role of low energy expenditure and sitting in obesity, metabolic syndrome, type 2 diabetes, and cardiovascular disease. Diabetes 56:2655-2667

7. O'Donovan G, Blazevich AJ, Boreham C et al (2010) The ABC of physical activity for health: a consensus statement from the British Association of Sport and Exercise Sciences. J Sports Sci 28:573-591

8. Warburton DE, Nicol CW, Bredin SS (2006) Health benefits of physical activity: the evidence. Can Med Assoc J 174:801-809

9. Ainsworth BE, Haskell WL, Whitt MC et al (2000) Compendium of physical activities: an update of activity codes and MET intensities. Med Sci Sports Exerc 32:S498-S504
10. Hamilton MT, Hamilton DG, Zderic TW (2004) Exercise physiology versus inactivity physiology: an essential concept for understanding lipoprotein lipase regulation. Exerc Sport Sci Rev 32:161-166

11. Hamer M, Stamatakis E, Steptoe A (2014) Effects of substituting sedentary time with physical activity on metabolic risk. Med Sci Sports Exerc. doi:10.1249/MSS.0000000000000317

12. Jakes R, Day N, Khaw K et al (2003) Television viewing and low participation in vigorous recreation are independently associated with obesity and markers of cardiovascular disease risk: EPIC-Norfolk population-based study. Eur J Clin Nutr 57: 1089-1096

13. Pulsford RM, Stamatakis E, Britton AR, Brunner EJ, Hillsdon MM (2013) Sitting behavior and obesity: evidence from the Whitehall II Study. Am J Prev Med 44:132-138

14. Healy GN, Matthews CE, Dunstan DW, Winkler EA, Owen N (2011) Sedentary time and cardio-metabolic biomarkers in US adults: NHANES 2003-06. Eur Heart J 32:590-597

15. Thorp AA, Healy GN, Owen $\mathrm{N}$ et al (2010) Deleterious associations of sitting time and television viewing time with cardiometabolic risk biomarkers: Australian Diabetes, Obesity and Lifestyle (AusDiab) study 2004-2005. Diabetes Care 33:327-334

16. Bankoski A, Harris TB, McClain JJ et al (2011) Sedentary activity associated with metabolic syndrome independent of physical activity. Diabetes Care 34:497-503

17. Ford ES, Kohl HW, Mokdad AH, Ajani UA (2005) Sedentary behavior, physical activity, and the metabolic syndrome among US adults. Obes Res 13:608-614

18. Petersen L, Schnohr P, Sørensen T (2003) Longitudinal study of the long-term relation between physical activity and obesity in adults. Int J Obes 28:105-112

19. Ekelund U, Brage S, Besson H, Sharp S, Wareham NJ (2008) Time spent being sedentary and weight gain in healthy adults: reverse or bidirectional causality? Am J Clin Nutr 88:612-617

20. Wilks D, Besson H, Lindroos A, Ekelund U (2011) Objectively measured physical activity and obesity prevention in children, adolescents and adults: a systematic review of prospective studies. Obes Rev 12:e119-e129

21. Laaksonen DE, Lakka H-M, Salonen JT, Niskanen LK, Rauramaa R, Lakka TA (2002) Low levels of leisure-time physical activity and cardiorespiratory fitness predict development of the metabolic syndrome. Diabetes Care 25:1612-1618

22. Lakka TA, Laaksonen DE (2007) Physical activity in prevention and treatment of the metabolic syndrome. Appl Physiol Nutr Metab 32: 76-88

23. Wijndaele K, Healy GN, Dunstan DW et al (2010) Increased cardiometabolic risk is associated with increased TV viewing time. Med Sci Sports Exerc 42:1511-1518

24. Wijndaele K, Orrow G, Ekelund U et al (2014) Increasing objectively measured sedentary time increases clustered cardiometabolic risk: a 6 year analysis of the ProActive study. Diabetologia 57:305-312

25. Hamilton MT, Healy GN, Dunstan DW, Zderic TW, Owen N (2008) Too little exercise and too much sitting: inactivity physiology and the need for new recommendations on sedentary behavior. Curr Cardiovasc Risk Rep 2:292-298

26. Sugiyama T, Healy GN, Dunstan DW, Salmon J, Owen N (2008) Joint associations of multiple leisure-time sedentary behaviours and physical activity with obesity in Australian adults. Int $\mathrm{J}$ Behav Nutr Phys Act 5:35

27. Maher CA, Mire E, Harrington DM, Staiano AE, Katzmarzyk PT (2013) The independent and combined associations of physical activity and sedentary behavior with obesity in adults: NHANES 2003-06. Obesity (Silver Spring) 21:e730-e737

28. Liao Y, Harada K, Shibata A et al (2011) Joint associations of physical activity and screen time with overweight among Japanese adults. Int J Behav Nutr Phys Act 8:1-5 
29. Boone JE, Gordon-Larsen P, Adair LS, Popkin BM (2007) Screen time and physical activity during adolescence: longitudinal effects on obesity in young adulthood. Int J Behav Nutr Phys Act 4:26

30. Marmot MG, Stansfeld S, Patel C et al (1991) Health inequalities among British civil servants: the Whitehall II study. Lancet 337: $1387-1393$

31. Taylor HL, Jacobs DR Jr, Schucker B, Knudsen J, Leon AS, Debacker G (1978) A questionnaire for the assessment of leisure time physical activities. J Chronic Dis 31:741-755

32. Albanes D, Conway JM, Taylor PR, Moe PW, Judd J (1990) Validation and comparison of eight physical activity questionnaires. Epidemiology 1:65-71

33. Folsom AR, Jacobs DR Jr, Caspersen CJ, Gomez-Marin O, Knudsen J (1986) Test-retest reliability of the Minnesota Leisure Time Physical Activity Questionnaire. J Chronic Dis 39:505-511

34. Katzmarzyk PT (2014) Standing and mortality in a prospective cohort of Canadian adults. Med Sci Sports Exerc 46:940-946

35. Hutcheon JA, Chiolero A, Hanley JA (2010) Random measurement error and regression dilution bias. BMJ 340:c2289

36. Healy GN, Wijndaele K, Dunstan DW et al (2008) Objectively measured sedentary time, physical activity, and metabolic risk the Australian Diabetes, Obesity and Lifestyle Study (AusDiab). Diabetes Care 31:369-371

37. Gardiner PA, Healy GN, Eakin EG et al (2011) Associations between television viewing time and overall sitting time with the metabolic syndrome in older men and women: the Australian Diabetes Obesity and Lifestyle Study. J Am Geriatr Soc 59:788-796

38. Bertrais S, Beyeme-Ondoua JP, Czernichow S, Galan P, Hercberg S, Oppert JM (2005) Sedentary behaviors, physical activity, and metabolic syndrome in middle-aged French subjects. Obes Res 13:936944

39. Helmerhorst HJ, Wijndaele K, Brage S, Wareham NJ, Ekelund U (2009) Objectively measured sedentary time may predict insulin resistance independent of moderate-and vigorous-intensity physical activity. Diabetes 58:1776-1779
40. Wennberg P, Gustafsson PE, Dunstan DW, Wennberg M, Hammarström A (2013) Television viewing and low leisure-time physical activity in adolescence independently predict the metabolic syndrome in mid-adulthood. Diabetes Care 36:2090-2097

41. Pereira SMP, Ki M, Power C (2012) Sedentary behaviour and biomarkers for cardiovascular disease and diabetes in mid-life: the role of television-viewing and sitting at work. PLoS One 7:e31132

42. Stamatakis E, Davis M, Stathi A, Hamer M (2012) Associations between multiple indicators of objectively-measured and selfreported sedentary behaviour and cardiometabolic risk in older adults. Prev Med 54:82-87

43. Dunstan DW, Salmon J, Owen N et al (2004) Physical activity and television viewing in relation to risk of undiagnosed abnormal glucose metabolism in adults. Diabetes Care 27:2603-2609

44. Dunstan DW, Salmon J, Owen N et al (2005) Associations of TV viewing and physical activity with the metabolic syndrome in Australian adults. Diabetologia 48:2254-2261

45. Owen N, Healy GN, Matthews CE, Dunstan DW (2010) Too much sitting: the population-health science of sedentary behavior. Exerc Sport Sci Rev 38:105

46. Maher C, Olds T, Mire E, Katzmarzyk PT (2014) Reconsidering the sedentary behaviour paradigm. PLoS One 9:e86403

47. Malik VS, Popkin BM, Bray GA, Després J-P, Willett WC, Hu FB (2010) Sugar-sweetened beverages and risk of metabolic syndrome and type 2 diabetes: a meta-analysis. Diabetes Care 33:2477-2483

48. Stamatakis E, Hamer M, Tilling K, Lawlor DA (2012) Sedentary time in relation to cardio-metabolic risk factors: differential associations for self-report vs accelerometry in working age adults. Int J Epidemiol 41:1328-1337

49. Celis-Morales CA, Perez-Bravo F, Ibanez L, Salas C, Bailey ME, Gill JM (2012) Objective vs. self-reported physical activity and sedentary time: effects of measurement method on relationships with risk biomarkers. PLoS One 7:e36345 